\title{
A PARTICIPAÇÃO DE IDOSOS EM ATIVIDADES RECREATIVAS EM ITABUNA/BA
}

Recebido em: 07/02/2012

Aceito em: 21/08/2012

Ana Luíza Borges da Silva ${ }^{1}$ Alexander Klein Tahara ${ }^{2}$ Sandro Carnicelli Filho ${ }^{3}$

Universidade Estadual de Santa Cruz - UESC Ilhéus - Bahia - Brasil

RESUMO: O objetivo desse estudo, de natureza quali-quantitativa, foi verificar a concepção de indivíduos idosos em relação às atividades recreativas, identificando as principais motivações, barreiras encontradas e benefícios advindos à sua participação em tais atividades. Foi aplicada uma entrevista semi-estruturada a 96 sujeitos entre 60 a 87 anos, de ambos os sexos e todos freqüentadores de uma unidade básica de saúde da cidade de Itabuna/BA. Os dados coletados foram analisados descritivamente, utilizandose a técnica de Análise de Conteúdo Temático.

PALAVRAS CHAVE: Idoso. Atividades de Lazer. Motivação.

\section{THE PARTICIPATION OF ELDERLY PEOPLE IN RECREATIONAL ACTIVITIES IN ITABUNA/BA}

ABSTRACT: The aim of this mix-methods study was to verify the perceptions of elderly people regarding recreational activities as well as to identify the motivations, perceived barriers and benefits of participation in these activities. A semi-structured interview was conducted with 96 male and female participants between 60 and 87 years old. The participants were regular patients of a health unity in Itabuna/BA. The data collected was descriptively analysed using the Thematic Content technique.

KEYWORDS: Aged. Leisure Activities. Motivation.

\footnotetext{
${ }^{1}$ Licenciada em Educação Física - UESC (Universidade Estadual de Santa Cruz - Ilhéus/BA)

${ }^{2}$ Docente do Curso de Educação Física da UESC (Universidade Estadual de Santa Cruz - Ilhéus/BA) e Membro do LEL - Laboratório de Estudos Lazer - UNESP/Rio Claro. email: alexipatinga@ yahoo.com

${ }^{3}$ Doutor em Filosofia (PhD) pelo Depto. Turismo da University Of Otago, New Zealand, e Membro do

LEL - Laboratório de Estudos do Lazer - UNESP/Rio Claro. email: sandro_unesp@ yahoo.com.br
} 


\section{INTRODUÇÃO}

A expectativa de vida no Brasil e no mundo vem crescendo progressivamente e, assim, o fenômeno do envelhecimento tem assumido uma grande importância em diferentes áreas profissionais, objetivando um maior conhecimento sobre o assunto e visando a implementação de ações que possam garantir uma boa qualidade na vida destes indivíduos idosos.

Nos últimos anos, foram realizados alguns estudos tais como Rodrigues (2002); Fenalti (2004); Silveira e Stigger (2007); Rezende (2008); entre outros, os quais se propõem a realizar debates e reflexões acerca da temática que se relaciona aos indivíduos idosos, ao lazer e à participação em atividades recreativas.

Devido aos declínios físico, mental e social característicos da população idosa (SANTOS FILHO, 2004), é de grande relevância a participação destes indivíduos em vivências que proporcionam o aumento da auto-estima e elevação dos níveis de bem estar físico e mental. Tudo isto tende a gerar como consequência uma melhoria da qualidade de vida, um aumento da autonomia funcional e o prazer pela vida, sendo que uma possibilidade para alcançar tais propósitos possa ser a participação em atividades recreativas.

De acordo com Suzuki (2005), o crescimento da população idosa em todo o mundo vem despertando o interesse de diversas áreas de estudo, pois geram conseqüências sociais importantes e revelam a grande necessidade de propor questões que visam um melhor desenvolvimento desta população.

Como alerta Rodrigues (2002), grande parte das pessoas idosas não tem acesso aos espaços de lazer, desconhecendo a importância e os benefícios que este pode lhe oferecer. Abrir possibilidades de acesso é fundamental, uma vez que só mediante 
Ana Luiza B. da Silva, Alexandre K. Tahara e Sandro Carnicelli Filho

experiências lúdicas e recreativas o idoso poderá aprender a gostar daquilo que efetivamente vivencia.

Tomando por base esses dados, deve-se haver uma necessidade de novos olhares para os indivíduos idosos, de tal maneira que se comece a visualizar como melhorar essa fase da vida, em todos os seus âmbitos, sejam eles fisiológicos, biológicos, afetivoemocional, entre outros, inclusive no que tange ao contexto do lazer e suas inúmeras possibilidades de usufruto, sendo uma delas a recreação.

Marcellino (2002) cita que pesquisas foram realizadas, tanto na Europa como nos Estados Unidos, dando conta de que os idosos são, comparativamente às pessoas de outras faixas etárias, os que menos frequentam equipamentos de lazer, ou participam de atividades recreativas e lúdicas. Comenta, ainda, que no Brasil tal fato não é muito diferente, devendo ser mais trabalhado e enfocado pelas áreas de conhecimento que realizam pesquisas nesta temática.

Assim, o objetivo desse estudo foi verificar a concepção de indivíduos idosos em relação às atividades recreativas na cidade de Itabuna/BA, identificando as principais motivações acerca da prática, as barreiras/dificuldades encontradas e os benefícios advindos à sua participação em tais vivências.

\section{MATERIAL E MÉTODO}

2.1. Área de estudo

Esta pesquisa foi realizada na Associação de Diabéticos da cidade de Itabuna (ASDITA), uma unidade de saúde localizada no centro da referida cidade, no estado da Bahia. 
Tal entidade é mantida pelo próprio município e sustentada com as mensalidades dos sócios, tendo como objetivo principal prestar serviços médicos às pessoas associadas, em especial diabéticas e hipertensas com diferentes faixas etárias.

A ASDITA oferece atendimento aos idosos em dois dias da semana - terça e quinta-feira - durante o período da manhã, com a promoção de diversos serviços como consultas rotineiras, aferição de pressão arterial e níveis de insulina, entre outros, não havendo o oferecimento de quaisquer tipos de vivências recreativas.

\subsection{Natureza e Tipologia da Pesquisa}

A pesquisa teve natureza quali-quantitativa, a qual segundo Thomas, Nelson e Silverman (2007) tem se tornado comum no meio científico e tem como característica não excluir a análise quantitativa. Combinando-se essas duas técnicas metodológicas qualitativa e quantitativa - há uma tendência em facilitar a visualização de pontos de convergência entre modelos diferentes, mostrando informações significativas e retirando dos dados o máximo de entendimento e sentido possível do objeto/área de estudo.

O método utilizado foi o descritivo, o qual apresenta como características analisar, descrever e correlacionar fatos sem manipulá-los, buscando identificar a freqüência em que um fato acontece e perceber sua relação com outros fatores (MATTOS, ROSSETTO JÚNIOR e BLECHER 2004).

A pesquisa descritiva, conforme comentam Cervo e Bervian (2002), pode ser classificada em diferentes formas. Esta especificamente é definida como um estudo exploratório visto que seu objetivo é se tornar íntima do fenômeno e descobrir novas 
percepções em relação ao objeto de estudo, no caso os indivíduos idosos e as atividades recreativas.

\subsection{Participantes}

Os sujeitos da referida pesquisa foram escolhidos aleatoriamente através de frequentes visitas na ASDITA durante o período de um mês nos dias de terça e quintafeira pela manhã, dias estes de atendimento específicos para indivíduos da terceira idade.

Torna-se importante comentar que esta aleatoriedade deveu-se ao fato de que nos dias de realizações das entrevistas havia um número de indivíduos que não quiseram responder às questões e nem se interessaram pela pesquisa. Dessa forma, entre os possíveis sujeitos que estavam na ASDITA nestes dias especificados durante um mês, ocorreu um convite de maneira aleatória para participação, naquele momento, da fase de coleta de dados. Assim, aqueles sujeitos que concederam anuência foram os que efetivamente o pesquisador pode entrevistar.

A seleção de amostra probabilística aleatória simples proporciona aos elementos da pesquisa chances iguais de serem incluídos na amostra. Deste modo, é garantido que os indivíduos serão selecionados aleatoriamente e não por escolha do pesquisador (MATTAR, 2001).

Assim, foram recrutados 96 indivíduos da terceira idade pacientes da ASDITA, localizado na cidade de Itabuna-BA. Os indivíduos apresentaram faixa etária variando entre 60 a 87 anos, sendo de ambos os sexos e distintos níveis de escolaridade e estado civil. Foi utilizado como critério de exclusão da pesquisa o fato dos sujeitos não possuir 
Ana Luiza B. da Silva, Alexandre K. Tahara e Sandro Carnicelli Filho

idade superior a 60 anos de idade e/ou não ser associado e frequentador da unidade de saúde.

\subsection{Procedimentos}

Inicialmente, para dar início à pesquisa exploratória, o pesquisador entrou em contato com o responsável pela ASDITA, explicando os reais intentos do estudo a ser desenvolvido. O pesquisador agendou visitas técnicas prévias e, desta forma, colheu informações sobre as atividades e a programação das mesmas.

Foi então apresentada uma Carta de Apresentação ao gestor da ASDITA, sendo solicitada autorização para a realização da pesquisa e, posteriormente ocorreu uma apresentação do próprio pesquisador aos pacientes da referida unidade de saúde em Itabuna/BA.

Em seguida, os idosos foram convidados a conhecer os objetivos da pesquisa, assim como o seu processo de desenvolvimento, o qual aconteceu através da aplicação de uma entrevista semi-estruturada, a fim de identificar a concepção dos idosos a respeito da prática de atividades recreativas e aspectos que permeiam sua participação. Antes, porém, foram convidados a conhecerem e assinarem o Termo de Consentimento Livre e Esclarecido (TCLE), para que dentro dos padrões éticos pudessem efetivamente participar da pesquisa.

O tempo médio de duração das entrevistas foi de seis minutos e vinte e cinco segundos e o local de realização foi na própria ASDITA. As respostas fornecidas pelos participantes foram armazenadas utilizando-se um gravador portátil e a seguir transcritas na íntegra, com o propósito de facilitar a análise e o acesso às respostas completas. 
No início da entrevista, foram evidenciados alguns dados pessoais dos participantes como idade, gênero, nível de escolaridade, entre outros e, a seguir foram apresentadas às questões propriamente ditas que compõem o estudo.

\subsection{Instrumento para a Coleta dos Dados}

Como instrumento para coleta dos dados foi utilizada uma entrevista semiestruturada construída especificamente para atender a proposta dessa pesquisa, a qual apresentou questões abertas e fechadas, fundamentadas na perspectiva de que os quesitos fechados proporcionam uma melhor facilidade na aplicação, bem como torna a entrevista menos cansativa aos indivíduos pesquisados. Por outro lado, os quesitos abertos permitem o entrevistado responder as questões com liberdade expondo mais sua opinião sobre a temática abordada.

Segundo Cervo e Bervian (2002), normalmente utilizam-se as questões abertas para as entrevistas e as fechadas para os questionários. No entanto, observa-se que não existe uma regra para tal uso, podendo ficar a cargo do pesquisador a devida utilização que melhor atenda aos objetivos do seu próprio estudo.

De acordo com Mattos, Rossetto Júnior e Blecher (2004), a entrevista semiestruturada se caracteriza pelo fato do investigador possuir uma lista de questões sobre determinado tema. No entanto, é possível ao entrevistador elaborar novas questões de acordo com as respostas obtidas no decorrer da entrevista. Dessa forma, percebe-se a configuração flexível que este instrumento de pesquisa possui na tentativa de se alcançar melhor os resultados. 


\subsection{Análise dos Dados}

Os dados coletados foram analisados descritivamente, por meio da técnica de Análise de Conteúdo Temático, sendo um instrumento que permite a descrição, a análise, a compreensão e a classificação dos processos vivenciados, conforme evidencia Richardson (1999), assimilando o que é realmente relevante para o estudo em questão.

Segundo Bardin (2004), após a realização da codificação de elementos do texto, obtidos através de entrevistas ou questionários, é possível calcular freqüências e relações que permitem traduzir as características das opiniões e respostas alcançadas.

É importante ressaltar que em algumas questões foi possível obter mais de um item a ser categorizado como resposta, dessa forma pode ser encontrada nos resultados um número de respostas maior do que o número total de sujeitos.

Posteriormente, as respostas foram reagrupadas por classificação temática e apresentadas através do diálogo com o referencial teórico para que, a partir daí, fosse possível descrever e refletir sobre as variáveis abordadas neste estudo.

Complementando esta análise descritiva, as informações e dados coletados foram apresentados por freqüência ou tabulação, no sentido de simplificar a interpretação e entendimento dos mesmos.

\section{RESULTADOS E DISCUSSÃO}

Antes de adentrar as discussões das questões norteadoras do estudo, tem-se a necessidade de traçar inicialmente o perfil (gênero e faixa etária; estado civil; nível de escolaridade; presença de doenças crônicas; profissões/ocupações; compromissos diários; motivos que fazem sair de casa) dos indivíduos idosos participantes da coleta de dados. 
O estudo contou com uma amostra de 96 sujeitos, de ambos os sexos, sendo 57 mulheres $(59,3 \%)$ e 39 homens $(40,7 \%)$, e a faixa etária variando entre 60 e 87 anos de idade.

Em relação ao estado civil percebe-se certo equilíbrio, onde 38 sujeitos $(39,58 \%)$ são viúvos, ao passo que 36 indivíduos (37,5\%) são casados e as outras 22 pessoas $(22,92 \%)$ são solteiras.

No que diz respeito ao nível de escolaridade, atenta-se para o fato de que a maioria possui pouca instrução relacionada à educação, sendo o Ensino Fundamental Incompleto o mais expressivo nas respostas $(n=42 ; 43,75 \%)$, os Analfabetos vêm na sequência $(n=37 ; 38,55 \%), \operatorname{logo}$ após o Ensino Fundamental Completo $(n=11 ; 11,45 \%)$ e Ensino Médio Incompleto $(n=6 ; 6,25 \%)$. Nota-se que nenhum indivíduo participante da pesquisa possui o Ensino Médio Completo nem o Ensino Superior (seja em andamento ou finalizado).

No que tange a presença de doenças crônicas diagnosticadas por médicos, a maioria dos entrevistados acusou possuir Hipertensão e Diabetes ( $\mathrm{n}=32 ; 31,69 \%)$, seguido somente pela Hipertensão $(n=27,26,73 \%)$, ao passo que somente Diabetes foi citado por 23 sujeitos $(22,77 \%)$, e por fim Osteoporose e Artrose (n=19; 18,81\%) Esta maior incidência deve-se ao fato de que todos os indivíduos pesquisados freqüentam um centro de atendimento a hipertensos e diabéticos da cidade de Itabuna/BA.

Com a presença das doenças crônicas e as conseqüentes limitações físicas e/ou psíquicas, os indivíduos idosos podem sofrer privações no que diz respeito à prática de atividades físicas ou recreativas. Martins, França e Kimura (1996) esclarecem que a hipertensão arterial, por exemplo, pode levar a uma alteração no estilo de vida das 
pessoas, principalmente pelas restrições impostas pelo tratamento farmacológico e cuidados necessários relacionados a este malefício.

O processo de envelhecimento, segundo os relatos de Oliveira (2000), é um processo natural ao qual todo e qualquer ser humano está submetido, e envolve uma variedade de transformações biopsicossociais que alteram sua relação com a sociedade em geral.

Sobre as suas profissões/ocupações, percebe-se que a maioria dos sujeitos ocupa funções direcionadas ao seu próprio lar, onde 37 pessoas $(38,6 \%)$ são responsáveis pelo ambiente doméstico, $(\mathrm{n}=28 ; 29,1 \%)$ são aposentados, $(\mathrm{n}=19 ; 19,8 \%)$ são agricultores e outros 12 indivíduos (12,5\%) são comerciantes.

Em referência aos principais compromissos e/ou responsabilidades que possuem no dia-a-dia, os afazeres domésticos $(n=36,37,5 \%)$ foram os mais citados, seguido pelas compras diversas $(n=27,28,12 \%)$, depois o fato de ter que cuidar de outras pessoas $(n=16,16,68 \%)$, os trabalhos voluntários que realizam $(n=12,12,5 \%)$ e o item “outros" como confecção de roupas, doces e derivados $(n=5,5,2 \%)$.

Sobre os motivos de maior frequência que impulsionam ao costume de ter que sair de casa, a igreja $(n=55,28,65 \%)$ foi a mais citada, num escore próximo à ida aos mercados $(n=52,27,08 \%)$, a seguir as visitas a terceiros $(n=38,19,8 \%)$, as atividades de lazer em geral $(n=24,12,5 \%)$, as viagens $(n=16,8,33 \%)$ e por fim as academias $(n=7$, $3,64 \%)$.

Desse modo, percebe-se que os indivíduos participantes da pesquisa ocupam mais o seu tempo disponível com as obrigações do dia-a-dia e com afazeres domésticos, sendo nítido que poucas pessoas frequentam/usufruem os espaços de lazer como viagens, academias e participação em vivências recreativas. 
Em consonância com a pesquisa, um estudo realizado por Suzuki (2005) encontrou dados equivalentes no que se refere aos principais compromissos e responsabilidades assumidas pelos idosos, indo ao encontro dos afazeres domésticos, preparação de refeições e serviços de ordem geral.

Sobre a concepção dos idosos a respeito do conceito de atividades recreativas, de acordo com a TAB. 1, os resultados mais expressivos mostram que eles entendem como atividades alegres e divertidas, bem como a participação em passeios e viagens.

TABELA 1

Concepção dos Idosos sobre o conceito de Atividades Recreativas

\begin{tabular}{|c|c|c|}
\hline Respostas & $\begin{array}{c}\text { Número de } \\
\text { Respostas (n=) }\end{array}$ & Porcentagem (\%) \\
\hline Atividades alegres e divertidas; Prazer & 36 & $26,67 \%$ \\
\hline Passeios em geral e Viagens & 28 & $20,74 \%$ \\
\hline Exercícios em grupo; cooperação e interação & 21 & $15,56 \%$ \\
\hline Não sei & 20 & $14,81 \%$ \\
\hline Contato com a natureza & 17 & $12,6 \%$ \\
\hline Caminhadas & 13 & $9,62 \%$ \\
\hline TOTAL & $\mathbf{1 3 5}$ & \\
\hline
\end{tabular}

De acordo com a ótica enfatizada por Steinheiber (1995), o lazer aparece na era contemporânea como uma característica do estilo de vida e, dentro dele, desenvolveram-se as "atividades recreativas", com significado associado à satisfação, ao prazer e alegria em tudo o que se vivencia nestas atividades.

Dias e Schwartz (2005), após investigarem em sua pesquisa grupos de aposentados em Rio Claro/SP, esclarecem que a diversão, o relaxamento, a felicidade e o prazer, entre outros, estão associados na vivência das atividades recreativas e dos momentos de lazer das pessoas. 
Ana Luiza B. da Silva, Alexandre K. Tahara e Sandro Carnicelli Filho

Assim, percebe-se que tanto a maioria dos indivíduos pesquisados quanto a literatura específica relacionam as atividades recreativas aos momentos de lazer em busca do prazer. Tais indivíduos, apesar do pouco grau de instrução educacional, apresentam uma concepção a respeito das atividades recreativas de certa forma correspondente aos estudos e autores da área em foco.

Conceitos expressos através de depoimentos coletados mostram que há tal associação entre atividades recreativas, lazer e prazer, sugeridos pela literatura específica:

"São passeios, momentos alegres e divertidos" (S. 21);

"São atividades de lazer que dão prazer às pessoas" (S. 5);

"São exercícios, caminhadas, a questão da participação em atividades em grupos" (S. 16).

Quanto a adesão à prática de atividades recreativas, conforme mostra a TAB.2, nota-se que infelizmente a maioria não vivencia tal oferta lúdica, embora entre aqueles indivíduos que são praticantes a TAB. 3 mostra que há uma boa incidência nesta participação.

TABELA 2

Adesão à prática de Atividades Recreativas

\begin{tabular}{|c|c|c|}
\hline Respostas & $\begin{array}{c}\text { Número de } \\
\text { Respostas (n=) }\end{array}$ & Porcentagem (\%) \\
\hline Não praticantes & 64 & $66,67 \%$ \\
\hline Praticantes & 32 & $33,33 \%$ \\
\hline TOTAL & $\mathbf{9 6}$ & $\mathbf{1 0 0 \%}$ \\
\hline
\end{tabular}


TABELA 3

Frequência de participação nas Atividades Recreativas

\begin{tabular}{|c|c|c|}
\hline Respostas & $\begin{array}{c}\text { Número de } \\
\text { Respostas }(\mathbf{n}=)\end{array}$ & Porcentagem (\%) \\
\hline 2 vezes/semanal & 17 & $53,12 \%$ \\
\hline 1 vez/semanal & 6 & $18,76 \%$ \\
\hline Às vezes/Nem toda semana & 5 & $15,62 \%$ \\
\hline Mais de 3 vezes/semanal & 4 & $12,5 \%$ \\
\hline TOTAL & $\mathbf{3 2}$ & $\mathbf{1 0 0 \%}$ \\
\hline
\end{tabular}

$\mathrm{Na}$ literatura existem algumas pesquisas sobre a prática de atividades físicas e a freqüência indicada para alcançar os benefícios proporcionados com a sua adesão. Segundo Nahas (2006), para indivíduos da terceira idade, inseridos como um grupo especial, recomenda-se exercícios moderados com duração de mais ou menos 30 a 50 minutos, pelo menos três vezes por semana.

No entanto, no que tange a frequência especificamente em atividades recreativas ainda são escassas as pesquisas neste sentido, uma vez que o fator considerado mais relevante refere-se a alcançar os objetivos advindos com a sua prática e não necessariamente quantas sessões semanais são realizadas.

De acordo com Iwanowicz (2000), a participação em atividades de lazer entre indivíduos idosos tem importante função de suporte social à medida que envolve o desenvolvimento de novas habilidades, experiências e conhecimentos, fatores estes culminantes para possibilitar uma autorrealização pessoal.

Um estudo qualitativo objetivou identificar aspectos emocionais na percepção de idosos, na adesão a vivências no lazer, sendo que os dados coletados mostram recorrências de crescimento positivo como a relação interpessoal e o respeito mútuo, a contemplação, a sensação de harmonia com a natureza, o elemento lúdico, entre outros, 
também responsáveis pelo vínculo afetivo do grupo em foco (GÁSPARI e SCHWARTZ, 2005).

Torna-se importante comentar que estas três próximas questões foram respondidas somente pelos 32 indivíduos que vivenciam as atividades recreativas, ficando impossibilitada a maioria $(n=64)$ por não participar regularmente de tais atividades e, consequentemente não ter conteúdo a ser relatado ao pesquisador. Ademais, estas 32 pessoas responderam mais de um item a ser categorizado por questão e, por isso, as porcentagens foram calculadas em função do número total de respostas coletadas.

Quanto às principais motivações que levam estes indivíduos a participar das atividades recreativas, a TAB. 4 mostra que as respostas mais expressivas incidem na justificativa de que as mesmas são prazerosas e alegres, além dos benefícios que tais vivências podem acarretar.

TABELA 4

Motivações em relação à participação nas Atividades Recreativas

\begin{tabular}{|c|c|c|}
\hline Respostas & $\begin{array}{c}\text { Número de } \\
\text { Respostas (n=) }\end{array}$ & Porcentagem (\%) \\
\hline Atividades prazerosas e alegres & 18 & $39,13 \%$ \\
\hline Benefícios a saúde física e mental & 11 & $23,91 \%$ \\
\hline Ter tempo disponível & 8 & $17,4 \%$ \\
\hline Companhia no momento das vivências & 5 & $10,86 \%$ \\
\hline São próximas do domicílio & 4 & $8,7 \%$ \\
\hline TOTAL & $\mathbf{4 6}$ & $\mathbf{1 0 0 \%}$ \\
\hline
\end{tabular}

Fenalti (2004) enfatiza que a possibilidade do contato com pessoas da mesma faixa etária, fuga da solidão, melhoria nos níveis de bem estar geral, o acompanhamento de amigos (as), entre outros, foram os principais motivos que levam os idosos a participar de projetos organizados com atividades físicas e recreativas. 
Alguns depoimentos emitidos a respeito dos motivos que levam os indivíduos a praticarem atividades recreativas, revelam que:

"Eu faço porque são atividades divertidas, alegres, prazerosas que deixa nosso corpo firme e com disposição" (S. 72),

"Tenho poucos compromissos, ainda faz bem a saúde do corpo e da mente, ai eu vou" (S. 50),

"Gosto de ir porque vou em companhia de amigas, ai chega lá encontramos mais e damos muito risada" (S. 31).

As principais motivações encontradas pelos sujeitos são condizentes com o conceito e com os objetivos proporcionados com a prática das atividades recreativas em geral.

Segundo Ferreira (2007), a atividade física praticada sobre a forma de recreação pode ser mais bem aceita pelo idoso, e conforme a adaptação ocorrer será mais fácil de inserir exercícios físicos com o intuito de criar gosto e prática à atividade física, e a partir de tal, possibilitar que o individuo tenha uma vida mais saudável.

Um estudo exploratório foi realizado com 151 idosos e os resultados indicam que a socialização torna-se sinônimo de lazer e constitui um dos principais motivos que levam estes indivíduos a praticá-lo. Através de programas como a extensão universitária, constatou-se que estes idosos têm mais disposição para realizar as atividades de vida diária, ocorre uma atenuação ou desaparecimento de dores preexistentes, há uma ampliação dos laços de amizade e redescoberta do sentido e prazer de continuar vivendo, além de possibilitar o encontro de novos parceiros (GOMES e PINTO, 2006).

De acordo com Lorda e Sanchez (1998) e Marcellino (2002), a prática de atividades recreativas na terceira idade proporciona diversos benefícios aos praticantes, sendo alguns deles o bem-estar físico, mental e social, assim como a promoção de um 
estilo de vida mais ativo e saudável, embora também possa haver uma série de empecilhos que podem dificultar tal assiduidade.

No que diz respeito às barreiras e/ou dificuldades encontradas para se manter uma participação regular nas atividades recreativas, os resultados são bastante equilibrados, como ilustra a (TAB. 5).

TABELA 5

Barreiras/Dificuldades encontradas na participação regular em Atividades Recreativas

\begin{tabular}{|c|c|c|}
\hline Respostas & $\begin{array}{c}\text { Número de } \\
\text { Respostas (n=) }\end{array}$ & Porcentagem (\%) \\
\hline Falta de lugares e programas específicos & 23 & $33,82 \%$ \\
\hline Desinteresse pessoal & 19 & $27,94 \%$ \\
\hline Problemas de saúde que impedem & 12 & $17,65 \%$ \\
\hline Falta de companhia para ir junto & 8 & $11,77 \%$ \\
\hline Questão econômica; Dificuldade financeira & 6 & $8,82 \%$ \\
\hline TOTAL & $\mathbf{6 8}$ & $\mathbf{1 0 0 \%}$ \\
\hline
\end{tabular}

Sobre o item mais expressivo na tabela acima, Melo e Alves Junior (2003) defendem que as cidades brasileiras devam ser cada vez mais humanizadas, onde haja ampliação de suas possibilidades de lazer diminuindo as desigualdades espaciais que reforçam as desigualdades quando se considera a distribuição dos equipamentos de lazer nos municípios.

Os sujeitos identificaram através de depoimentos que:

"Me sinto muito cansada e também não conheço nenhum lugar, principalmente que não se pague" (S. 7);

"Falta tempo para praticar essas atividades, porque são muitas ocupações diárias, além do mais nunca tive interesse em procurar" (S. 88);

"Devido às doenças que aparecem eu prefiro ficar em casa mesmo, ir dormir, descansar e ler a bíblia” (S. 10).

Dentre as barreiras que impossibilitam a concretização do ideal de lazer na população idosa podem-se citar os estereótipos, a questão econômica, o tempo 
disponível e o acesso aos espaços de lazer (RODRIGUES, 2002). A mesma autora ainda afirma que o tempo livre representa uma barreira á prática de atividades recreativas e de lazer, pois relata que os idosos estão envolvidos com uma série de obrigações familiares, religiosas e sociais que limitam o tempo a ser destinado ao lazer.

No entanto, o fator "tempo disponível" não foi citado com uma dificuldade na participação em atividades recreativas e de lazer por nenhum dos sujeitos estudados e sim os resultados mais expressivos mostram como justificativa a dificuldade em encontrar locais que promovam a prática de atividades recreativas para os idosos.

Marcellino (2002) comenta que há muito a ser feito para que este grupo populacional se constitua em faixa etária privilegiada para a vivência do lazer, uma vez que se trata de justiça social, devendo haver um acesso facilitado aos equipamentos e políticas públicas que oportunizem efetivamente a participação em atividades de lazer.

As dificuldades financeiras dos idosos, as condições precárias de saúde e a perda gradual do hábito de procurar opções de lazer em ambiente externo, constituem, também, outros impedimentos relevantes para a inserção em diversas práticas, pois, na idade adulta, um novo conjunto de papéis sociais e responsabilidades, provocam uma mudança nos hábitos de lazer e então, o tempo livre passa a ser sempre mais ocupado pelo exercício de outras funções, deixando para um segundo plano as vivências práticas no contexto do lazer (DIAS e SCHWARTZ, 2003).

Cabe ressaltar que, apesar da segunda resposta mais expressiva corresponder ao desinteresse pela vivência em atividades recreativas, os indivíduos identificaram bem o conceito e os objetivos propostos pela participação nas atividades, bem como a consideram importantes na melhoria da qualidade de vida física e mental. Com isso, acredita-se que pela dificuldade no acesso a essas atividades e por não conhecerem na 
efetiva prática, os sujeitos percebem como uma barreira a falta de locais específicos, além do próprio desinteresse pessoal.

Com relação aos benefícios proporcionados com a prática das atividades recreativas, como mostra a TAB. 6 , todos os sujeitos consideram que a participação em tais atividades seja importante em algum aspecto.

TABELA 6

Benefícios proporcionados pela participação em Atividades Recreativas

\begin{tabular}{|c|c|c|}
\hline Respostas & $\begin{array}{c}\text { Número de } \\
\text { Respostas (n=) }\end{array}$ & Porcentagem (\%) \\
\hline Melhoria na saúde física e mental & 48 & $47,52 \%$ \\
\hline Integração e Socialização; Conhecer pessoas & 27 & $26,73 \%$ \\
\hline Alegria e Diversão; Prazer & 15 & $14,85 \%$ \\
\hline Elevação da auto-estima & 11 & $10,9 \%$ \\
\hline TOTAL & $\mathbf{1 0 1}$ & $\mathbf{1 0 0 \%}$ \\
\hline
\end{tabular}

De acordo com Santos Filho (2004), as atividades recreativas são atividades inerentes à boa convivência dos grupos de terceira idade, capaz de propiciar bem-estar e prazer aos praticantes. $\mathrm{O}$ mesmo autor ressalta que tais atividades apresentam cunho lúdico, podendo ser um fator importante para que as pessoas possuam uma vida com mais qualidade através de vivências significativas e prazerosas.

Aproximando-se agora da relação entre programas de atividade física, idosos e lazer, Krug et al. (2011) enfatizam que o aumento da disposição e da alegria, melhoria do bem-estar e níveis de humor, diminuição das dores nas pernas e maior socialização, entre outros, estão entre as possíveis contribuições da caminhada como atividade de lazer para os idosos.

Ainda sobre tal relação, Serri e Simões (2007) compararam motivos que impulsionam dois grupos de idosos que praticam hidroginástica em duas cidades 
distintas (Piracicaba/SP/Brasil e Fort Collins/EUA). Alertam que foi possível perceber que são vários os motivos que levam os idosos a buscar a hidroginástica, embora o fator mais citado pelos participantes de Piracicaba tenha sido por ordens médicas ou em função de problemas de saúde, enquanto em Fort Collins os indivíduos iniciaram essa atividade por si só, mostrando-se muito consciente em relação aos benefícios para a saúde ligados à participação em atividade física regular.

No caso da presente pesquisa os depoimentos de alguns indivíduos atestam o reconhecimento de diversos benefícios advindos da participação em atividades recreativas e de lazer, como:

"Ajuda principalmente na saúde, a pessoa fica com disposição para fazer tudo" (S. 62);

"Ativa a mente, melhora na circulação, o corpo precisa se movimentar, pois ficar parado é prejudicial” (S. 50);

"Minha filha tem depressão, quando ela começou a se distrair em aulas de bordado ela ficou bem melhor" (S. 3).

Pylro e Rossetti (2005) acrescentam que as atividades recreativas e de lazer nos dias atuais podem ser consideradas uma necessidade de qualquer pessoa e em qualquer idade, pois estas atividades além de serem prazerosas, também contribuem na facilitação da aprendizagem, colaboram para uma boa saúde mental, facilitam os processos de socialização e comunicação, contribuem no desenvolvimento pessoal, cultural e social, além de ajudar na expressão e construção do conhecimento.

A resposta mais expressiva nesta pesquisa para os benefícios advindos com a prática de atividades recreativas está relacionada com a melhoria da saúde física e mental. Contudo, acredita-se que através dessas atividades é possível gastar energia corporal e trabalhar o aspecto intelectual desenvolvendo tais aspectos na vida dos praticantes. 
Assim, de acordo com Waichman (2004) uma experiência recreativa deve haver uma disponibilidade de energia psíquica e biológica para que os envolvidos participem integralmente das atividades. No entanto, esta pré-disposição a adesão as atividades pode ser adquirida gradativamente com a prática e conseqüentemente possibilitar uma melhora na qualidade de vida.

Em detrimento à relação "qualidade de vida e atividades de lazer", um estudo mostra correlação direta entre essa variável e os domínios físico e psicológico do WHOQOL-Bref (World Health Organization Quality of Life). Apesar de grande diferença de indivíduos entre os grupos que realizam $(92,6 \%)$ e os que não realizam $(7,4 \%)$ atividades de lazer, o primeiro grupo apresentou escores melhores de Qualidade de Vida nos domínios acima citados, demonstrando que uma maior interação social pode elevar os níveis de qualitativos de vida (FARENZENA et al., 2007).

No que tange a interação e socialização, Silveira e Stigger (2007) afirmam que espaços de sociabilidade lúdica apresentam como característica propiciar aos seus frequentadores uma rede de relações sociais, que proporcionam significados qualitativos diferenciados ao processo natural de envelhecimento.

\section{CONSIDERAÇÕES FINAIS}

Os objetivos deste trabalho foram alcançados, visto que a proposta de investigação permitiu verificar claramente a concepção de pessoas idosas acerca da temática das atividades recreativas, identificando as motivações, barreiras encontradas e benefícios acarretados na adesão à prática de tais atividades.

No decorrer da pesquisa houve algumas limitações que impediram a coleta de uma maior quantidade de dados na unidade básica de saúde, ASDITA, localizada na 
cidade de Itabuna/BA. Houve uma relativa resistência dos indivíduos em responder à entrevista semi-estruturada, sendo realizadas explicações mais susceptíveis em linguagem adequada à dos indivíduos, assim como executadas leitura clara e objetiva do termo de consentimento livre e esclarecido a fim de facilitar a concordância dos sujeitos em participar da pesquisa.

Os resultados apresentados neste trabalho indicam que os idosos freqüentadores da unidade básica de saúde, ASDITA, apresentam uma concepção acerca das atividades recreativas condizente com a preconizada pela literatura existente, bem como percebem os diversos benefícios proporcionados com a sua prática.

Porém, é possível observar o pouco envolvimento da população estudada na prática de tais atividades. Fato considerável que pode estar associado a pouca disposição de projetos/programas gratuitos disponíveis para este grupo populacional e, ademais o pouco interesse pessoal por parte dos indivíduos parece ter contribuído com o baixo índice de participação nas atividades recreativas. Fica evidente que apesar dos sujeitos possuírem certo conhecimento sobre as atividades recreativas, sua importância e seus benefícios, ainda é observada como baixa a participação destes indivíduos em tais atividades. Diante dos dados coletados, pode-se dizer que talvez seja necessária a construção e implantação de projetos/programas em Itabuna/BA que apresentam como objetivo proporcionar momentos de recreação e lazer voltados especificamente para este público alvo.

Sobre isso, Gomes e Pinto (2006) esclarecem que há necessidades de investimentos no campo do lazer, requerendo um maior investimento na criação de políticas e programas (públicos e privados) para os idosos, sem deixar de apoiar e 
desenvolver os projetos já existentes, considerando as questões empreendedoras e de autonomia destes indivíduos.

Espera-se que os resultados alcançados sejam utilizados para a conscientização e promoção de atividades recreativas voltadas aos idosos, além do intuito deste trabalho em fomentar a importância da prática de tais atividades para a manutenção da saúde física, mental e social destes indivíduos.

\section{REFERÊNCIAS}

BARDIN, L. Análise de conteúdo. 3. ed. Lisboa: Edições 70, 2004.

CERVO, A. L.; BERVIAN, P. A. Metodologia científica. 5. ed. São Paulo: Prentice Hall, 2002.

DIAS, V. K.; SCHWARTZ, G. M. Emoção, aventura e o idoso: visão das agências de ecoturismo. In: ENCONTRO NACIONAL DE RECREAÇÃO E LAZER, 15, 2003, Santo André. Anais... São Paulo: SESC, 2003. CD-ROOM.

DIAS, V. K.; SCHWARTZ, G. M. O lazer na perspectiva do indivíduo idoso. Lécturas: Educación Física e Deportes, Bueno Aires, v. 10, n. 87, ago. 2005. Disponível em: http://www.efdeportes.com/efd87/idos.htm. Acesso em: 15 ago. 2012.

FARENZENA, W. P.; et al. Qualidade de vida em um grupo de idosos de Veranópolis. Kairós, São Paulo, v. 10, n. 2, p. 225-243, dez. 2007.

FENALTI, R. C. S. A conduta lúdica e a terceira idade. In: SCHWARTZ, G. M. (Org.) Dinâmica Lúdica: novos olhares. Barueri: Manole, 2004. p. 87-107.

FERREIRA, V. Atividade Física na $3^{\text {a }}$ Idade: o segredo da longevidade. 2. ed. Sprint: Rio de Janeiro, 2007.

GÁSPARI, J. C.; SCHWARTZ, G. M. O idoso e a ressignificação emocional do lazer. Psicologia: Teoria e Pesquisa, Brasília, v. 21 n. 1, p. 69-76, 2005.

GOMES, C. L.; PINTO, G. B. O lazer na velhice: reflexão sobre as experiências de um grupo de idosos. Kairós, São Paulo, v. 9, n. 2, p. 113-133, dez. 2006.

IWANOWICZ, J. B. O lazer do idoso e o desenvolvimento prossocial. In: BRUHNS, H.T. (Org.) Temas sobre lazer. Campinas: Autores Associados, 2000.

KRUG, R. R.; et al. Contribuições da caminhada como atividade física de lazer para idosos. Licere, Belo Horizonte, v.14, n.4, p.01-29, dez/2011. 
LORDA, C. R.; SANCHEZ, C. D. Recreação na terceira idade. 2. ed. Rio de Janeiro: Sprint, 1998.

MARCELLINO, N. C. Estudos do lazer: uma introdução. 3. ed. Campinas: Autores Associados, 2002.

MARTINS, L. M.; FRANÇA, A. P. D. ; KIMURA, M. Qualidade de vida de pessoas com doença crônica. Revista Latino-Americana de Enfermagem, v. 4, n. 3, p. 5-8, 1996.

MATTAR, F. N. Pesquisa de Marketing. 3. ed. São Paulo: Atlas, 2001.

MATTOS, M. G.; ROSSETTO JÚNIOR, A. J.; BLECHER, S. Teoria e prática da metodologia da pesquisa em educação física: construindo sua monografia, artigo científico e projeto de ação. São Paulo: Phorte, 2004.

MELO, V. A.; ALVES JUNIOR, E. D. Introdução ao lazer. Barueri: Manole, 2003.

NAHAS, M. V. Atividade física, saúde e qualidade de vida: conceitos e sugestões para um estilo de vida ativo. 4. ed. Londrina: Midiograf, 2006.

OLIVEIRA, Y. A. D. O lazer do idoso. In: RODRIGUES, R. A. P.; DIOGO, M. J. D.(Org.) Como cuidar dos idosos. 2. ed. Campinas: Papirus, 2000. p. 113-119.

PYLRO. C. S.; ROSSETTI. C. B. Atividades Lúdicas, Gênero e Vida Adulta. PsicoUSF, Bragança Paulista, n.10, v.1. p. 77-86, 2005.

REZENDE, R. Afeto, Velhice e Lazer. Licere, Belo Horizonte, v.11, n.3, p. 1-21, dez./2008.

RICHARDSON, R. J. Pesquisa social: métodos e técnicas. 3. ed. São Paulo: Atlas, 1999.

RODRIGUES, M. C. O lazer do idoso: barreiras a superar. Revista Brasileira de Ciências e Movimento, Brasília, v. 10, n. 4, p.105-108, 2002.

SANTOS FILHO, J. A. A. Atividades recreativas e envelhecimento. In: SCHWARTZ, G. M. (Org.) Atividades recreativas. Rio de Janeiro: Guanabara Koogan, 2004. p.156165.

SERRI, A. S.; SIMÕES, R. Hidroginástica e Idosos: por que eles praticam? Movimento, Porto Alegre, v.13, n. 01, p.81-92, 2007.

SILVEIRA, R.; STIGGER, M. P. Espaço de Jogo - Espaço de Envelhecimento: sociabilidade lúdica na Sociedade Esportiva Recanto da Alegria. Revista Brasileira de Ciências do Esporte, Campinas, v. 29, n. 1, p. 177-192, set. 2007.

STEINHEIBER, J. Colônia de férias: organização e administração. Rio de Janeiro: Sprint, 1995. 
SUZUKI, C. S. Aderência à atividade física em mulheres da Universidade Aberta á Terceira Idade. 2005. 104f. Dissertação (Mestrado) - Escola de Enfermagem, Universidade de São Paulo, Ribeirão Preto, 2005.

THOMAS, J. R.; NELSON, J. K.; SILVERMAN, S. J. Métodos de pesquisa em atividade física. 5. ed. Porto Alegre: Artmed, 2007.

WAICHMAN, P. A. A respeito dos enfoques em recreação. Revista da Educação Física/UEM, Maringá, v. 15, n. 2, p. 22-31, 2004.

\section{Endereço dos autores:}

Ana Luíza Borges da Silva

Alexander Klein Tahara

Sandro Carnicelli Filho

UESC - Universidade Estadual de Santa Cruz

Depto. Ciências da Saúde (DCSau)

Rodovia Ilhéus-Itabuna, Km 16, Salobrinho

Ilhéus/BA - CEP: 45662-000

Endereço Eletrônico: alexipatinga@yahoo.com 